Abstract

\title{
Survey of the Apoptotic Effect of Ginnalin A on Hep3b Human Hepatocellular Carcinoma Cell Line ${ }^{\dagger}$
}

\author{
Pınar Özden *, Ebru Avcı and Hasibe Vural \\ Department of Medical Biology, Meram Faculty of Medicine, Necmettin Erbakan University, \\ Konya 42060, Turkey \\ * Correspondence: pnarozden@gmail.com; Tel.: +90-332-223-7214 \\ + Presented at the 2nd International Conference on Natural Products for Cancer Prevention and Therapy, \\ Kayseri, Turkey, 8-11 November 2017.
}

Publish: 15 November 2017

\begin{abstract}
Hepatocellular carcinoma is the third most common cause of cancer-related deaths worldwide. Ginnalin A (GA) is one of the most important phenolic compounds of maple syrup and its anticancer effect has been shown that in several cancer cell lines. In this study, objective was to investigate the apoptotic effect of GA in Hep3B human hepatocellular carcinoma cell line. Cell viability was determined by using XTT method after the treatment with GA. Total RNA was isolated with TRIzol Reagent in control and dose group. Expressions of important genes in apoptosis including CASP3, CASP8, CASP9, CYCS, FAS and P53 were evaluated by qPCR. IC 50 dose of GA was found as $155 \mu \mathrm{M}$ for $72 \mathrm{~h}$ in Hep3B cells. According to the qPCR results, a significant increase in the expression of CASP3, CASP8, CASP9, CYCS and P53 genes was observed as 12.09, 10.14, 3.37, 16.15 and 4.15 folds, respectively. In conclusion, it is thought that GA demonstrates the apoptotic effect on Hep3B human hepatocellular carcinoma cell line. GA can be evaluated as an effective anticancer agent in hepatocellular carcinoma after further molecular and functional analysis.
\end{abstract}

Keywords: Apoptosis; Ginnalin A; Hep3B cell line

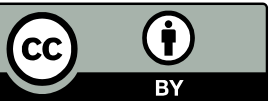

(C) 2017 by the authors. Licensee MDPI, Basel, Switzerland. This article is an open access article distributed under the terms and conditions of the Creative Commons Attribution (CC BY) license (http://creativecommons.org/licenses/by/4.0/). 